Article

\title{
Ionization and Attachment Coefficients in $\mathrm{C}_{4} \mathrm{~F}_{7} \mathrm{~N}$ Gas Measured by the Steady-State Townsend Method
}

\author{
Zhaoyu Qin ${ }^{1}$, Yunxiang Long ${ }^{2, *}$, , Zhenyu Shen ${ }^{2}$, Cheng Chen ${ }^{2}$, Liping Guo ${ }^{2, *}$ and \\ Wenjun Zhou ${ }^{3}$ \\ 1 Wuhan NARI Limited Company of State Grid Electric Power Research Institute, Wuhan 430074, China \\ 2 Hubei Key Laboratory of Nuclear Solid Physics, Key Laboratory of Artificial Micro- and Nano-structures of \\ Ministry of Education and School of Physics and Technology, Wuhan University, Wuhan 430072, China \\ 3 School of Electrical Engineering and Automation, Wuhan University, Wuhan 430072, China \\ * Correspondence: kobe-long@whu.edu.cn (Y.L.); guolp@whu.edu.cn (L.G.)
}

Received: 15 August 2019; Accepted: 3 September 2019; Published: 5 September 2019

\begin{abstract}
The normalized Townsend first ionization coefficient $\alpha / N$ and normalized attachment coefficient $\eta / \mathrm{N}$ in pure $\mathrm{C}_{4} \mathrm{~F}_{7} \mathrm{~N}$ were measured by using the steady-state Townsend (SST) method for a range of reduced electric fields $E / N$ from 750 to $1150 \mathrm{Td}$ at room temperature $\left(20^{\circ} \mathrm{C}\right)$. Meanwhile, the effective ionization coefficients are obtained. All SST experimental results show good agreement with pulsed Townsend (PT) experiment results. Comparisons of the critical electric fields of $\mathrm{C}_{4} \mathrm{~F}_{7} \mathrm{~N}$ with $\mathrm{SF}_{6}$ and other alternative gases such as $\mathrm{c}-\mathrm{C}_{4} \mathrm{~F}_{8}$ and $\mathrm{CF}_{3} \mathrm{I}$ indicate that $\mathrm{C}_{4} \mathrm{~F}_{7} \mathrm{~N}$ has a better insulation performance with a much higher normalized critical electric field at $959.19 \mathrm{Td}$.
\end{abstract}

Keywords: $\mathrm{C}_{4} \mathrm{~F}_{7} \mathrm{~N}$; ionization coefficient; attachment coefficient; critical electric field; steady-state Townsend method; ionization; plasma; gas discharge; high voltage; $\mathrm{SF}_{6}$

\section{Introduction}

As is well known, sulfur hexafluoride $\left(\mathrm{SF}_{6}\right)$, with a good insulation performance and thermal stability, is widely used as an insulation gas and arc quenching medium in many fields such as high-voltage engineering and electrical power applications [1,2]. Unfortunately, as one of the six greenhouse gases, $\mathrm{SF}_{6}$ has an extremely high global warming potential $\left(\mathrm{GWP}_{100}\right)$ at 23,500 times that of $\mathrm{CO}_{2}$ [3]. Thus, in order to slow down global warming, searching for an environment-friendly insulation gas to reduce the use of $\mathrm{SF}_{6}$ is of great importance.

During the last decades, there has been some research about the discharge characteristics of $c-\mathrm{C}_{4} \mathrm{~F}_{8}$ [4-6] and $\mathrm{CF}_{3} \mathrm{I}$ [7-9], which have been thought of as potential alternative gases to $\mathrm{SF}_{6}$. Recently, as another newly potential substitutional insulation gas of $\mathrm{SF}_{6}$, fluoronitriles $\left(\mathrm{C}_{4} \mathrm{~F}_{7} \mathrm{~N}\right.$, also known as $3 \mathrm{M}$ Novec-4710), which have a GWP value of 2100 , have been designed and have attracted great attention [10]. Although $\mathrm{C}_{4} \mathrm{~F}_{7} \mathrm{~N}$ gas has a good insulation performance, because of its high boiling temperature, it has to be mixed with other buffer gases such as $\mathrm{CO}_{2}$ to adapt to the operating conditions under high gas pressure [11]. Nevertheless, it is worthy to obtain the basic electron swarms of $\mathrm{C}_{4} \mathrm{~F}_{7} \mathrm{~N}$, such as the ionization coefficient $\alpha$ and attachment coefficient $\eta$, which can be used to evaluate the insulation performance of gases [12]. 
However, it should be noted that there has been less investigation on the ionization coefficients and attachment coefficients in $\mathrm{C}_{4} \mathrm{~F}_{7} \mathrm{~N}$. It has been reported once that the normalized effective ionization coefficient $(\alpha-\eta) / N$ within a small range of reduced electric fields (per gas density $N$ ) $E / N$ was obtained with the steady-state Townsend (SST) method by Nechmi et al. [13]. The electron rate and transport coefficients in pure $\mathrm{C}_{4} \mathrm{~F}_{7} \mathrm{~N}$ were obtained with the pulsed Townsend (PT) method by Chachereau et al. [14]. In the present work, both normalized ionization and normalized attachment coefficients, as well as effective ionization coefficients of $\mathrm{C}_{4} \mathrm{~F}_{7} \mathrm{~N}$, were measured by the SST method, a kind of method which has been widely used to measure these coefficients in different gases like $\mathrm{SF}_{6}$ [15-17], c- $\mathrm{C}_{4} \mathrm{~F}_{8}$ [4], $\mathrm{CF}_{3} \mathrm{I}$ [8], and so on. It should also be noticed that although the SST method has been well developed during the last decades, and the innovation of the method itself may not be high, the experiments using this method to measure and obtain the discharge parameters and evaluate the insulation abilities of new insulation gases are still significant.

\section{Experiments}

The experiments were carried out on an SST apparatus setup in Wuhan University, which the details have been described in previous work [18,19]. The reliability of this SST apparatus has been verified by experiments on known gases such as $\mathrm{SF}_{6}$ and $\mathrm{N}_{2}$, which showed this SST apparatus has great measurement accuracy $(<2 \%)[19]$. The theoretical equations used to obtain the experimental results have been introduced as well. Through the update of vacuum-tight gaskets, the background vacuum degree in the ionization chamber can reach $\sim 1.0 \times 10^{-5} \mathrm{~Pa}$ at room temperature with a leak rate less than $0.10 \mathrm{~Pa} / \mathrm{h}$, which can minimize the effect of the pressure change on experimental results. In the present study, the range of reduced electric fields $E / N$ applied for the SST experiment varied from 750 to $1150 \mathrm{Td}\left(1 \mathrm{Td}=10^{-21} \mathrm{Vm}^{2}\right)$, since the insulation performance of $\mathrm{C}_{4} \mathrm{~F}_{7} \mathrm{~N}$ is much better than $\mathrm{SF}_{6}$ as reported [13,14]. The purity of $\mathrm{C}_{4} \mathrm{~F}_{7} \mathrm{~N}$ gas (produced by Beijing Yuji Science and Technology Co., Ltd., China) used in the present study was more than $99.6 \%$, and the impurities were mainly air $(\sim 0.3 \%)$. The gas pressure was $500 \mathrm{~Pa}$ at $20^{\circ} \mathrm{C}$. The initial electron current $I_{0}$ of the electron avalanche was about $4 \mathrm{pA}$, and current $I$ in the nonself-sustained discharge stage was also on the order of picoampere (pA).

\section{Results and Discussion}

\subsection{Ionization and Attachment Coefficients}

The normalized ionization coefficient $\alpha / \mathrm{N}$ and the attachment coefficient $\eta / N$ of $\mathrm{C}_{4} \mathrm{~F}_{7} \mathrm{~N}$ gas for $750 \mathrm{Td}<E / \mathrm{N}<1150 \mathrm{Td}$ were measured respectively. The results were compared to that $\mathrm{Sf}_{6}$ gas and shown in Figure 1. It was found that with an increasing $E / N$, the $\alpha / N$ of $C_{4} F_{7} N$ showed a growing trend, while the $\eta / N$ showed a clear decreasing trend, which were similar to that of $\mathrm{SF}_{6}$ [3]. Meanwhile, compared to $\mathrm{SF}_{6}$ gas, it was apparent that the values of $\eta / \mathrm{N}$ in $\mathrm{C}_{4} \mathrm{~F}_{7} \mathrm{~N}$ were much higher than that of $\mathrm{SF}_{6}$ for the same $E / N$, which could be explained with the attachment cross-sections in different gases. The higher the attachment cross section is, the stronger the ability of electron attachment is. The total attachment cross-sections of $\mathrm{C}_{4} \mathrm{~F}_{7} \mathrm{~N}[14], \mathrm{SF}_{6}[9]$, and other gases $[9,20]$ have been compared and plotted in Figure 2. As reported [14], the total attachment cross-section in $\mathrm{C}_{4} \mathrm{~F}_{7} \mathrm{~N}$ was larger than that of $\mathrm{SF}_{6}$ above $0.1 \mathrm{eV}$, while the values of $\alpha / \mathrm{N}$ were a little bit smaller than that of $\mathrm{SF}_{6}$ when $E / N<900 \mathrm{Td}$. When $E / N>900 \mathrm{Td}$, the values of $\alpha / \mathrm{N}$ in $\mathrm{C}_{4} \mathrm{~F}_{7} \mathrm{~N}$ were a little bit higher than that of $\mathrm{SF}_{6}$. Therefore, for $\mathrm{C}_{4} \mathrm{~F}_{7} \mathrm{~N}$ and $\mathrm{SF}_{6}$ with similar values of ionization coefficients, $\mathrm{C}_{4} \mathrm{~F}_{7} \mathrm{~N}$ had a better insulation performance due to the much higher attachment coefficient than that of $\mathrm{SF}_{6}$. 


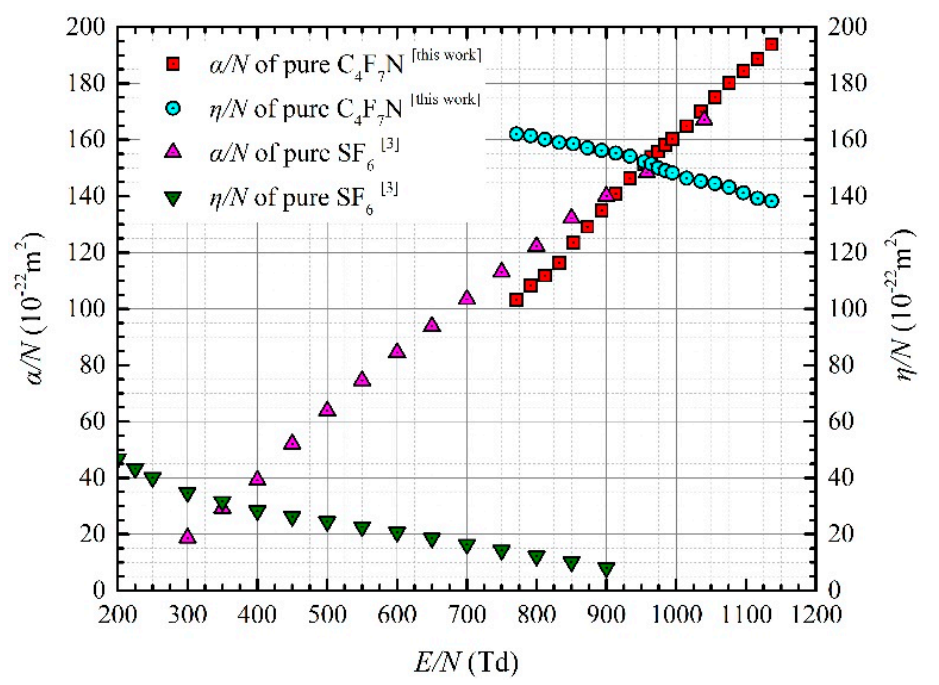

Figure 1. Values of $\alpha / N$ and $\eta / N$ as a function of $E / N$ in $C_{4} F_{7} N$ gas in the present work and their comparison to $\mathrm{SF}_{6}$ gas.

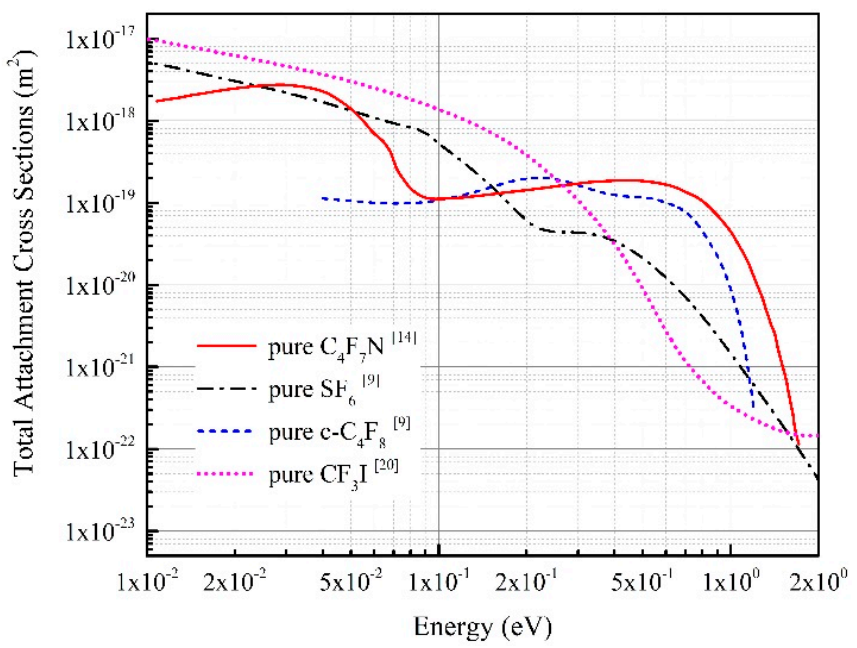

Figure 2. Comparison of total attachment cross-sections of $\mathrm{C}_{4} \mathrm{~F}_{7} \mathrm{~N}, \mathrm{SF}_{6}, \mathrm{c}-\mathrm{C}_{4} \mathrm{~F}_{8}$, and $\mathrm{CF}_{3} \mathrm{I}$.

The $\alpha / N$ and $\eta / N$ measured by the SST method in this work have also been compared to the PT method measured by Chachereau et al. [14], which are plotted in Figure 3. It should be noted that the values of $\alpha / N$ and $\eta / N$ used for comparisons with the PT method were not given directly in Chachereau's work; they were calculated from parameters such as electron drift velocity $\left(w_{\mathrm{e}}\right)$, ionization rate coefficient $\left(k_{\mathrm{i}}\right)$, and attachment rate coefficient $\left(k_{\mathrm{a}}\right)$. It can be found that the trends of varying $\alpha / N$ and $\eta / N$ in this work showed good agreement with PT experiments. Significantly, the fluctuation of PT was much larger than that of SST, which may be caused by the different experimental principles and conditions, such as a much lower pressure (100 Pa), in the PT experiment.

\subsection{Effective Ionization Coefficients}

The normalized effective ionization coefficient $(\alpha-\eta) / \mathrm{N}$ of $\mathrm{C}_{4} \mathrm{~F}_{7} \mathrm{~N}$, in a range of $E / \mathrm{N}$ from 750 to $1150 \mathrm{Td}$, at $20^{\circ} \mathrm{C}$ was obtained as well. Figure 4 presents the value $(\alpha-\eta) / \mathrm{N}$ as a function of $E / N$ in $\mathrm{C}_{4} \mathrm{~F}_{7} \mathrm{~N}$, and its comparisons with $\mathrm{SF}_{6}[3], \mathrm{c}_{-} \mathrm{C}_{4} \mathrm{~F}_{8}$ [4], $\mathrm{CF}_{3} \mathrm{I}[7], \mathrm{C}_{4} \mathrm{~F}_{7} \mathrm{~N}[13,14]$, and $\mathrm{C}_{4} \mathrm{~F}_{7} \mathrm{~N} / \mathrm{N}_{2}$ mixtures [18] are reported. Notably, the $E / N$ of $\mathrm{C}_{4} \mathrm{~F}_{7} \mathrm{~N}$ was much greater than other kinds of gases for the same $(\alpha-\eta) / N$, which suggests that the insulation ability of $\mathrm{C}_{4} \mathrm{~F}_{7} \mathrm{~N}$ is much stronger. Once the $\mathrm{C}_{4} \mathrm{~F}_{7} \mathrm{~N}$ gas mixed with buffer gas $\mathrm{N}_{2}$, the insulation performances of the mixtures were much weaker than pure $\mathrm{C}_{4} \mathrm{~F}_{7} \mathrm{~N}$, since $\mathrm{N}_{2}$ is an electrically neutral gas whose attachment coefficients is 0 . Meanwhile, 
the variety of $(\alpha-\eta) / N$ with $E / N$ showed a linear trend for all these gases nearby the normalized critical electric field $(E / N)_{\text {lim }}$ (for $\alpha-\eta=0$ ). Moreover, compared to the data reported, our results of normalized effective coefficients in $\mathrm{C}_{4} \mathrm{~F}_{7} \mathrm{~N}$ were in good agreement with that of Nechmi et al. [13] as well as Chachereau [14]. Meanwhile, more values in the $E / N$ that varied from 750 to $1150 \mathrm{Td}$ were obtained in the present work.
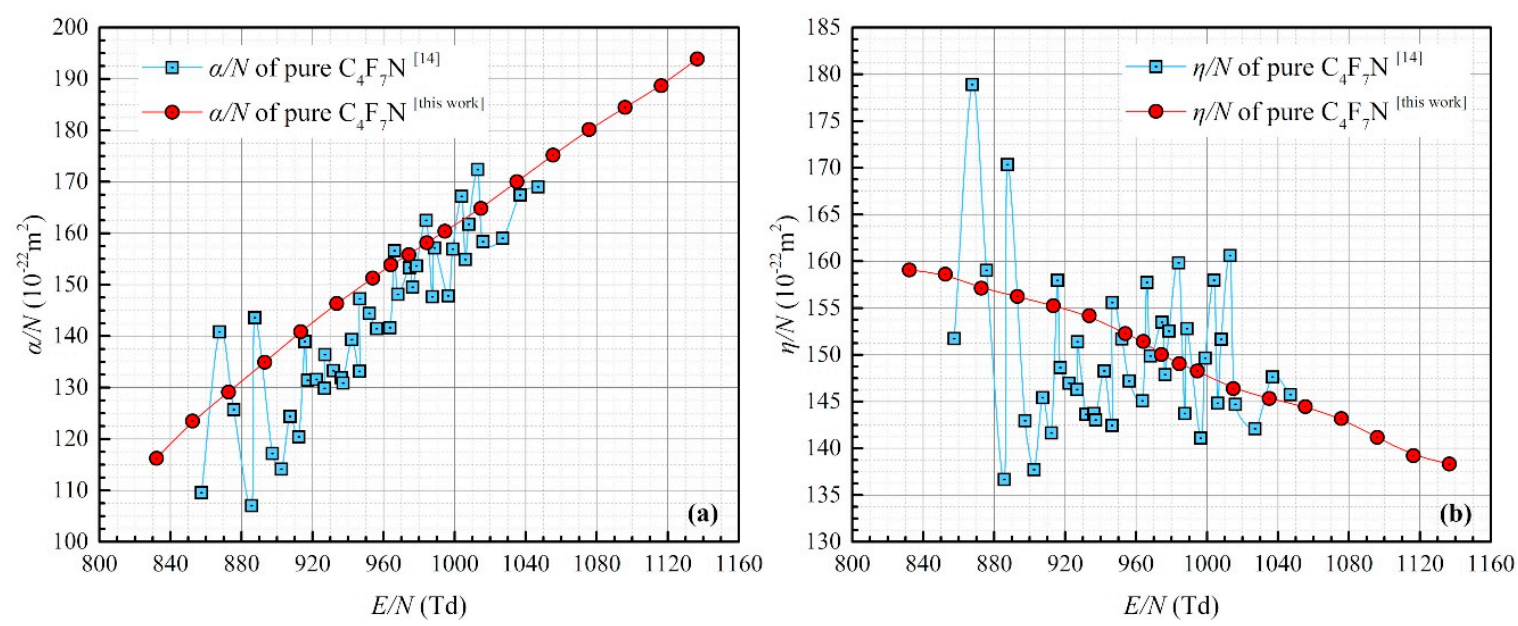

Figure 3. (a) Comparison of values of $\alpha / N$ measured with the steady-state Townsend (SST) method in this work and the pulsed Townsend (PT) method [14]; (b) Comparison of values of $\eta / N$ measured with SST method in this work and PT method [14].

According to the bond length values of the $\mathrm{C}_{4} \mathrm{~F}_{7} \mathrm{~N}$ molecule [21], the structure of the $\mathrm{C}_{4} \mathrm{~F}_{7} \mathrm{~N}$ molecule could be drawn as in Figure 5. A recent study [22] shows that the bonds of C-1 to C-2 and $\mathrm{C}-1$ to $\mathrm{C}-3$ have the smallest bond energy, which is $3.812 \mathrm{eV} /$ atom. The second smallest bond energy is $4.556 \mathrm{eV} /$ atom, which belongs from C-1 to F-1. The bond energy of S-F in $\mathrm{SF}_{6}$ is $3.432 \mathrm{eV} /$ atom, which is smaller than the smallest bond energy in $\mathrm{C}_{4} \mathrm{~F}_{7} \mathrm{~N}$. It is well known that the smaller the bond energy is, the weaker the interaction between atoms will be. Since the $\mathrm{C}_{4} \mathrm{~F}_{7} \mathrm{~N}$ and $\mathrm{SF}_{6}$ molecules have a strong ability to attach electrons, they can easily adsorb electrons and, hence, become negatively charged molecules. Then, these charged molecules could accelerate under an electric field, applied between two plate electrodes, and collide with other molecules. Thus, the collision may lead to the breaking of weak bonds and forming new particles such as $\mathrm{F}$ in $\mathrm{SF}_{6}$ and $\mathrm{CF}_{3}$ in $\mathrm{C}_{4} \mathrm{~F}_{7} \mathrm{~N}$. For the same electric field, the bonds of $\mathrm{SF}_{6}$ are easier to be broken than bonds $\mathrm{C}-1$ to $\mathrm{C}-2$ (or $\mathrm{C}-3$ ) of $\mathrm{C}_{4} \mathrm{~F}_{7} \mathrm{~N}$. Consequently, the new particles formed in the $\mathrm{SF}_{6}$ gas, such as $\mathrm{F}$, would further take part in the discharging process. However, the $\mathrm{CF}_{3}$ formed in $\mathrm{C}_{4} \mathrm{~F}_{7} \mathrm{~N}$ more easily adorbs electrons than the $\mathrm{F}$ formed in $\mathrm{SF}_{6}$, since there is more $\mathrm{F}_{\text {in }} \mathrm{CF}_{3}$, and fluorine has strong electronegativity. Then, $\mathrm{SF}_{6}$ is more likely to exhibit ionization characteristics, which could lead to the higher effective ionization coefficients of $\mathrm{SF}_{6}$ than that of $\mathrm{C}_{4} \mathrm{~F}_{7} \mathrm{~N}$ for the same $E / N$. 


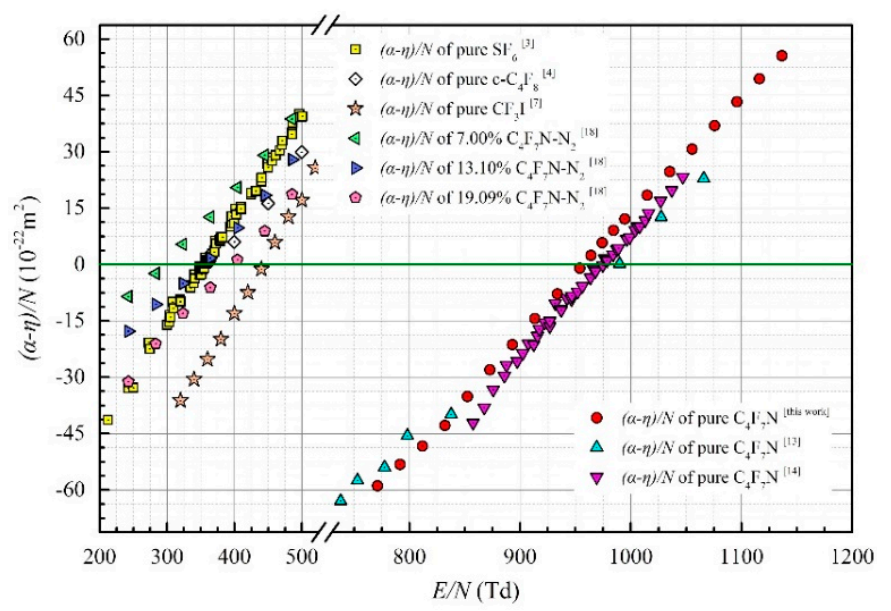

Figure 4. Comparison of the normalized effective ionization coefficient in different gases.

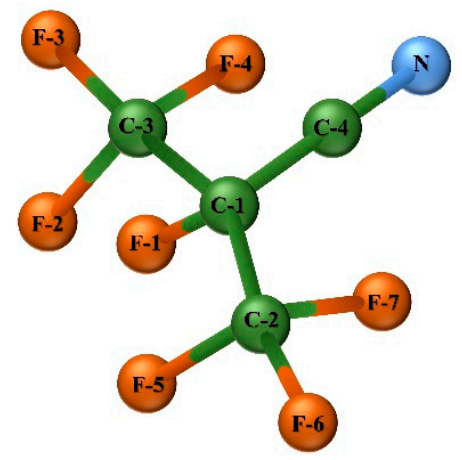

Figure 5. The molecule structure of $\mathrm{C}_{4} \mathrm{~F}_{7} \mathrm{~N}$ gas.

\subsection{Critical Electric Fields}

In order to more clearly compare and evaluate the insulation performance quantitatively, the $(E / N)_{l i m}$ of these four gases have been sorted out in Table 1. It is apparent that $C_{4} F_{7} \mathrm{~N}$ has a superior performance of gas insulation, as it had a high $(E / N)_{l i m}$ value $(959.19 \mathrm{Td})$. The relative deviation of $(E / N)_{\text {lim }}$ of $\mathrm{C}_{4} \mathrm{~F}_{7} \mathrm{~N}$ measured in this work was about $2.41 \%$ of that measured by Nechmi et al. [13] and was about $1.73 \%$ of that measured by Chachereau et al. [14], which could testify that the experiments in the present study were of high credibility at the same time. Furthermore, it could be found that the value of $(E / N)_{l i m}$ of $\mathrm{C}_{4} \mathrm{~F}_{7} \mathrm{~N}$ was about 2.68 times that of pure $\mathrm{SF}_{6}$ gas. However, the dielectric strength of $\mathrm{C}_{4} \mathrm{~F}_{7} \mathrm{~N}$ at atmospheric pressure was about 2 times that of $\mathrm{SF}_{6}$ as reported [10], slightly less than 2.68 times, which could be caused by different behaviors of ion kinetics under different gas pressures [14]. The higher the gas pressure, the greater the effect of ion kinetics.

Table 1. The values of $(E / N)_{\text {lim }}$ in different gases.

\begin{tabular}{cc}
\hline Gas Type & $(\mathrm{E} / \mathrm{N})_{\text {lim }} / \mathrm{Td}$ \\
\hline $\mathrm{C}_{4} \mathrm{~F}_{7} \mathrm{~N}$ & 959.19 [present work] \\
& $981.84[13]$ \\
& $975[14]$ \\
$\mathrm{C}^{-} \mathrm{C}_{4} \mathrm{~F}_{8}$ & $408.68[4]$ \\
$\mathrm{CF}_{3} \mathrm{I}$ & $440.19[7]$ \\
$\mathrm{SF}_{6}$ & $355.27[13]$ \\
& $358.66[14]$ \\
& $351.80[16]$ \\
\hline
\end{tabular}




\section{Conclusions}

In the present work, both the $\alpha / \mathrm{N}$ and $\eta / \mathrm{N}$ in $\mathrm{C}_{4} \mathrm{~F}_{7} \mathrm{~N}$ have been measured by using the SST method for $E / N$ from 750 to $1150 \mathrm{Td}$ at $20{ }^{\circ} \mathrm{C}$, and they were compared to that of pure $\mathrm{SF}_{6}$ gas. Moreover, the value of $(\alpha-\eta) / N$ was obtained for $750 \mathrm{Td}<E / N<1150 \mathrm{Td}$. All results measured by the SST method showed good agreement with PT experiments. The critical electric field $(E / N)_{\lim }$ of $\mathrm{C}_{4} \mathrm{~F}_{7} \mathrm{~N}$ was about $959.19 \mathrm{Td}$. The comparison indicated that the insulation performance of $\mathrm{C}_{4} \mathrm{~F}_{7} \mathrm{~N}$ is superior to that of $\mathrm{SF}_{6}$, and $\mathrm{C}_{4} \mathrm{~F}_{7} \mathrm{~N}$ could be considered as a candidate insulation gas to replace $\mathrm{SF}_{6}$ in the high-voltage engineering field.

Author Contributions: Conceptualization, Y.L. and L.G.; data curation, Z.Q. and Y.L.; formal analysis, Z.S. and C.C.; investigation, Z.Q. and Y.L.; methodology, Z.Q. and C.C.; project administration, W.Z.; validation, Z.Q., Y.L. and Z.S.; writing—original draft preparation, Z.Q.; writing—review and editing, Y.L. and L.G.

Funding: This research was funded by the National Key R\&D Program of China (2017YFB0902500) and the Science \& Technology Project of State Grid Corporation of China (The Key Technology of Environment-Friendly Gas-Insulated Transmission Line).

Acknowledgments: The financial support of this work was from the National Key R\&D Program of China (2017YFB0902500), and the Science \& Technology Project of State Grid Corporation of China (The Key Technology of Environment-Friendly Gas-Insulated Transmission Line) is gratefully acknowledged. The authors sincerely thank Yu Jianhui from the School of Electrical Engineering and Automation, Wuhan University, who gave guidance in the experiments in this paper.

Conflicts of Interest: The authors declare no conflict of interest.

\section{References}

1. Christophorou, L.G.; Van Brunt, R.J. $\mathrm{SF}_{6} / \mathrm{N}_{2}$ Mixtures Basic and HV Insulation Properties. IEEE Trans. Dielectr. Electr. Insul. 1995, 2, 952-1003. [CrossRef]

2. Dincer, M.S.; Raju, G.G. Ionization and Attachment Coefficients in $\mathrm{SF}_{6}+\mathrm{N}_{2}$ Mixtures. IEEE Trans. Electr. Insul. 1984, EI-19, 40-44. [CrossRef]

3. Christophorou, L.G.; Olthoff, J.K. Electron Interactions with $\mathrm{SF}_{6}$. J. Phys. Chem. Ref. Data 2000, 29, 267-330. [CrossRef]

4. Yamaji, M.; Nakamura, Y.; Morokuma, Y. Measurements of ionization and attachment coefficients in $0.468 \%$ and $4.910 \% \mathrm{c}_{-} \mathrm{C}_{4} \mathrm{~F}_{8} / \mathrm{Ar}$ mixtures and pure $\mathrm{c}_{-} \mathrm{C}_{4} \mathrm{~F}_{8}$. J. Phys. D Appl. Phys. 2004, 37, 432-437. [CrossRef]

5. de Urquijo, J.; Basurto, E. Electron attachment, ionization and drift in $\mathrm{c}^{-} \mathrm{C}_{4} \mathrm{~F}_{8}$. J. Phys. D Appl. Phys. 2001, 34, 1352-1354. [CrossRef]

6. Naidu, M.S.; Prasad, A.N.; Craggs, J.D. Electron transport, attachment and ionization in $\mathrm{c}-\mathrm{C}_{4} \mathrm{~F}_{8}$ and iso- $\mathrm{C}_{4} \mathrm{~F}_{8}$. J. Phys. D Appl. Phys. 1972, 5, 741-746. [CrossRef]

7. Li, X.; Zhao, H.; Wu, J.; Jia, $\mathrm{S}$. Analysis of the insulation characteristics of $\mathrm{CF}_{3} \mathrm{I}$ mixtures with $\mathrm{CF}_{4}, \mathrm{CO}_{2}, \mathrm{~N}_{2}$, $\mathrm{O}_{2}$ and air. J. Phys. D Appl. Phys. 2013, 46, 345203-345210. [CrossRef]

8. Hasegawa, H.; Date, H.; Shimozuma, M.; Itoh, H. Properties of Electron Swarms in CF 3 I. Appl. Phys. Lett. 2009, 95, 101504-101506. [CrossRef]

9. Raju, G.G. Gaseous Electronics: Tables, Atoms, and Molecules; CRC Press Taylor \& Francis Group: Boca Raton, FL, USA, 2012.

10. Kieffel, Y.; Irwin, T.; Ponchon, P.; Owens, J. Green Gas to Replace $\mathrm{SF}_{6}$ in Electrical Grids. IEEE Power Energy Mag. 2016, 14, 32-39. [CrossRef]

11. Kieffel, $\mathrm{Y}$; Biquez, F.; Poncho, P. Alternative gas to $\mathrm{SF}_{6}$ for use in high voltage switchgears: $\mathrm{g}^{3}$. In Proceedings of the 23rd International Conference on Electricity Distribution (CIRED), Lyon, France, 15-18 June 2015; p. 230.

12. Townsend, J.S. The Conductivity produced in Gases by the Motion of Negatively-charged Ions. Nature 1900, 62, 340-341. [CrossRef]

13. Nechmi, H.E.; Beroual, A.; Giodet, A.; Vinson, P. Effective Ionization Coefficient and Limiting Field Strength of Fluoronitriles- $\mathrm{CO}_{2}$ Mixtures. IEEE Trans. Dielectr. Electr. Insul. 2017, 24, 886-892. [CrossRef]

14. Chachereau, A.; Hösl, A.; Franck, C.M. Electrical insulation properties of the perfluoronitrile $\mathrm{C}_{4} \mathrm{~F}_{7} \mathrm{~N}$. J. Phys. D Appl. Phys. 2018, 51, 495201-495210. [CrossRef] 
15. Bhalla, M.S.; Craggs, J.D. Measurement of Ionization and Attachment Coefficients in Sulphur Hexafluoride in Uniform Fields. Proc. Phys. Soc. 1962, 80, 151-160. [CrossRef]

16. Raju, G.G.; Dincer, M.S. Measurement of ionization and attachment coefficients in $\mathrm{SF}_{6}$ and $\mathrm{SF}_{6}+\mathrm{N}_{2}$. J. Appl. Phys. 1982, 53, 8562-8567. [CrossRef]

17. Fréchette, M.F. Experimental study of $\mathrm{SF}_{6} / \mathrm{N}_{2}$ and $\mathrm{SF}_{6} / \mathrm{CCl}_{2} \mathrm{~F}_{2}$ mixtures by the steady-state Townsend method. J. Appl. Phys. 1986, 59, 3684-3693. [CrossRef]

18. Long, Y.; Guo, L.; Shen, Z.; Chen, C.; Chen, Y.; Li, F. Ionization and Attachment Coefficients in $\mathrm{C}_{4} \mathrm{~F}_{7} \mathrm{~N} / \mathrm{N}_{2}$ Gas Mixtures for Use as a Replacement to $\mathrm{SF}_{6}$. IEEE Trans. Dielectr. Electr. Insul. 2019, 26, 1358-1362. [CrossRef]

19. Long, Y.; Guo, L.; Shen, Z.; Chen, C.; Zhou, W.; Liu, W. Investigation of Ionization Characteristics of $\mathrm{C}_{4} \mathrm{~F}_{7} \mathrm{~N}-\mathrm{N}_{2}$ Gas Mixtures as Alternative Gas to $\mathrm{SF}_{6}$ by Steady-state Townsend Method. High Volt. Eng. 2019, $45,1064-1070$.

20. Christophorou, L.G.; Olthoff, J.K. Electron Interactions with CF $_{6}$ I. J. Phys. Chem. Ref. Data 2000, $29,553-569$. [CrossRef]

21. Li, Y.; Zhang, X.; Xiao, S.; Chen, Q.; Tang, J.; Chen, D.; Wang, D. Decomposition Properties of $\mathrm{C}_{4} \mathrm{~F}_{7} \mathrm{~N} / \mathrm{N}_{2}$ Gas Mixture: An Environmentally Friendly Gas to Replace SF 6 . Ind. Eng. Chem. Res. 2018, 57, 5173-5182. [CrossRef]

22. Wang, C.; Wu, Y.; Sun, H.; Duan, J.; Niu, C.; Yang, F. Thermophysical Properties Calculation of $\mathrm{C}_{4} \mathrm{~F}_{7} \mathrm{~N} / \mathrm{CO}_{2}$ mixture Based on Computational Chemistry-A Theoretical Study of $\mathrm{SF}_{6}$ Alternative. In Proceedings of the 4th International Conference on Electric Power Equipment-Switching Technology (ICEPE-ST), Xi'an, China, 22-25 October 2017; pp. 255-258.

(C) 2019 by the authors. Licensee MDPI, Basel, Switzerland. This article is an open access article distributed under the terms and conditions of the Creative Commons Attribution (CC BY) license (http://creativecommons.org/licenses/by/4.0/). 